Andrzej Wilk
Dr hab. inż., prof. nadzw.PG
Politechnika Gdańska, Katedra
Inżynierii Elektrycznej
Transportu
andrzej.wilk@pg.edu.pl

\section{Cezary Specht}

Prof. dr hab. inż.

Uniwersytet Morski w Gdyni, Katedra Geodezji i

Oceanografii

c.specht@wn.umg.edu.pl

\author{
Władysław Koc \\ Prof. dr hab. inż. \\ Politechnika Gdańska, Katedra \\ Transportu Szynowego i \\ Mostów \\ kocwl@pg.edu.pl
}

\section{Krzysztof Karwowski}

Dr hab. inż., prof. nadzw. PG

Politechnika Gdańska, Katedra

Inżynierii Elektrycznej

Transportu

krzysztof.karwowski@pg.edu. $\mathrm{pl}$

\author{
Chrostowski Piotr \\ Politechnika Gdańska, Katedra \\ Transportu Szynowego i \\ Mostów \\ piotr.chrostowski@pg.edu.pl
}

\section{Jacek Szmagliński}

Politechnika Gdańska, Katedra

Transportu Szynowego i

Mostów

jacek.szmaglinski@pg.edu.pl

\section{Paweł Dąbrowski \\ Mgr inż.}

Uniwersytet Morski w Gdyni,

Katedra Geodezji i

Oceanografii

p.dabrowski@wn.umg.edu.pl

\section{Mariusz Specht}

Mgr inż.

Uniwersytet Morski w Gdyni,

Katedra Transportu i Logistyki

m.specht@wn.umg.edu.pl

\author{
Sławomir Judek \\ Politechnika Gdańska, Katedra \\ Inżynierii Elektrycznej \\ Transportu \\ slawomir.judek@pg.edu.pl
}

\section{Jacek Skibicki}

Politechnika Gdańska, Katedra

Inżynierii Elektrycznej

Transportu

jacek.skibicki@pg.edu.pl

\author{
Marcin Skóra \\ Mgr inż. \\ Uniwersytet Morski w Gdyni, \\ Katedra Geodezji i \\ Oceanografii \\ marcin21@gmail.com
}

\author{
Sławomir Grulkowski \\ Politechnika Gdańska, Katedra \\ Transportu Szynowego i \\ Mostów \\ slawomir.grulkowski@pg.edu. \\ $\mathrm{pl}$
}

DOI: 10.35117/A_ENG_19_07_04

\title{
Research project BRIK: development of an innovative method for determining the precise trajectory of a railway vehicle
}

\begin{abstract}
In the paper the essential assumptions regarding a research project implemented by a consortium of Gdansk University of Technology and Gdynia Maritime University are presented. The project has been commissioned by National Center of Research and Development with cooperation with Polish Railways (PKP Polskie Linie Kolejowe S.A.).

The project is focused in implementation of modern measurement techniques using Global Navigation Positioning System GNSS, Inertial Navigation System INS and Mobile Laser Scanning MLS in a railway network management process. The precise aim of the research is both determine geometric parameters of a railway geometric layout as well as a railway vehicle movement trajectory. For this reason the innovative technique of mobile satellite measurements will be used. In the paper a synthetic description of the project together with the particular stages are presented. Also, a part of research which was realized in 2018 is shown. In the first stage, Gdansk University of Technology made a research of existing common methods for determining and assessing a track alignment, presented an idea of mobile investigation of track axis by the use of satellite measurements, took into consideration an issue of influence of dynamic behavior of the measurement vehicle on the accuracy of determined track positions by the use of GNSS/INS techniques and finally presented a technical project of measurement platform. Gdynia Maritime University made a query of GNSS/INS/MLS in measurements of track alignment, elaborated a scheme of measurement devices placement on the mobile measurement platform and studied possibilities of increasing accuracy for estimation a railway vehicle localization in relation to common techniques used by polish train operators.
\end{abstract}

Keywords: Research project; Railway layout; GNSS/INS/MLS measurements 


\section{Introduction}

For a long time, there has been a belief that in the era of dynamically developing systems for positioning using GNSS [11], it becomes possible to develop a reliable and accurate method for determining the shape of the rail track axis in the National Geodetic Coordinate System 2000 [9]. The thesis presented was explicitly confirmed by research work carried out since 2009 by an interdisciplinary scientific team composed primarily of employees of the Gdańsk University of Technology and the Naval Academy in Gdynia. Currently, AMW employees participating in the project belong to the staff of the Maritime University in Gdynia. Over the years, the team has carried out a series of measurement campaigns in the railway track in operation, which are the basis for the development of an innovative technique of mobile satellite measurements and new methods of designing track geometric systems using this technique. The results of the conducted research were disseminated on an ongoing basis in dozens of publications, both domestic and foreign (among others [3-6, 14-16]), which allowed for a comprehensive presentation of the new measuring technique in the scientific and engineering environment dealing with the field of rail transport infrastructure. The effect summarizing the achievements to date in this field is a monograph book publication [7].

These experiences became the basis for successful participation in the competition organized by the National Center for Research and Development and PKP Polskie Linie Kolejowe S. A. Application for co-financing No. POIR.04.01.01-00-0017/17 "The development of an innovative method for determining the precise trajectory of a rail vehicle" (acronym: InnoSatTrack) was submitted by the Consortium of the Gdańsk University of Technology (Leader) and the Maritime University in Gdynia (implemented as part of the BRIK Joint Undertaking in the Intelligent Development Operational Program 2014-2020, implementation period 2018.06.24 -2021.05.31).

As part of the Gdańsk University of Technology, the project is implemented by employees of the Department of Electrical Engineering of Transport, Faculty of Electrical Engineering and Automation as well as the Chair of Rail and Bridge Transport, Faculty of Civil and Environmental Engineering. On the part of the Gdynia Maritime University, the employees of the Department of Geodesy and Oceanography from the Faculty of Navigation participate in the project.

The project concerns the issue of reproducing the geometric shape of railway lines by means of mobile satellite measurements. The precise identification of the track axis entails a number of possibilities related to the updating of digital data about the location of lines and engineering objects in the 2000 coordinate system. This data can also be used for planning, designing and building databases for infrastructure management and as input for pass counting programs theoretical trains. The GNSS technique also allows the location of rail vehicles in real-time (location, speed) e.g. for traffic control purposes or as a data source for passenger information systems.

The adopted research area will allow determining the current and future possibilities of using GNSS techniques (and inertial techniques complementing them) in the abovementioned fields. A wide range of experimental research and laboratory work will be preceded by an analysis of the adopted assumptions and study works. The latest generation of measuring equipment will be used to implement the project, along with the use of the existing reference station network in Poland. Various variants of the measurement system configuration with the optimization of its critical parameters will be analyzed. Finally, the track axis will be represented by a number of geometrical parameters, in accordance with the principles of defining and identifying geometrical systems of railway tracks. The measurement results will be processed in a multilayered IT system developed as part of the project, which will allow their presentation in a functional web application. 


\section{The InnoSat Track project description}

The project involves the use of modern measurement methods, such as GNSS positioning techniques [11], INS inertial measurements [2] and LS laser scanning [8], in the management of the railroad network. The management process is understood here as a series of tasks related to both planning, designing, building and maintaining railway lines, as well as those related to running trains. The latest achievements in this field prove that the potential of satellite positioning techniques opens up previously unknown possibilities related to the precise determination of track position relative to the adopted spatial reference system. Therefore, there is a possibility of quick - in relation to traditional geodesy based on the total station - mapping of the railway line shape. Two issues should be distinguished, namely the reconstruction of the geometrical system of railway lines and the reconstruction of the trajectory of rail vehicle movement, despite the fact that the equivalence of these terms is most often assumed. However, this is based on treating the actual track formation in a model way (full compliance with the technical documentation) or on the possibility of identifying the geometric system with an ambiguously determined trajectory of the vehicle movement (e.g. in discrete terms - a set of points, or in vector terms using glued functions). In the described project these aspects are separated. The geometrical system of the railway line will be represented by a set of theoretical models identified in the course of measurements and numerical analyses, in accordance with the principles of railway line design, while the vehicle's trajectory will be mapped with a certain accuracy based on the actual location of the vehicle at a given time. Both of these issues have their own assumptions and limitations, as well as specific criteria for the accuracy requested.

To determine the track axis in the context of the geometric system, the following assumptions and technical requirements must be met:

- The measurement will be made during the journey at a speed for which the positioning density is approximately 2-4 per linear meter of a track (i.e. every $25-50 \mathrm{~cm}$ ). This assumption is related to the ambiguity of positioning of geometric elements (straight lines, circular arcs, transition curves, longitudinal slopes, etc.) along the length of the line. These elements can be reproduced with the desired accuracy only with sufficient density of positioning;

- The measurement results will be aligned using a base in the form of a set of vectors defined relative to the measurement platform (Fig. 1). This methodology will allow maximum utilization of the complex measuring system (a set of parallel GNSS antennas) for the purposes of improving the accuracy of track axis positioning. The measurement signal obtained in this way will be properly prepared for further geometric analysis;

- GNSS positions will be confronted with the signal of inertial devices, which will also reduce the degree of uncertainty associated with the random deterioration of satellite signal quality. The methodology based on INS sensors will be used especially in situations of loss of satellite signal availability resulting from field screens in the form of nearby buildings, excavations, wooded areas, viaducts, bridges, tunnels, etc.;

- Geometric elements and their parameters will be identified assuming that the differences between the positions of the aligned satellite measurement and the coordinates of the identified geometric system are minimized. The differences determined in this way will be analyzed in the context of the degree of deformation of the geometric system relative to the theoretical model. 


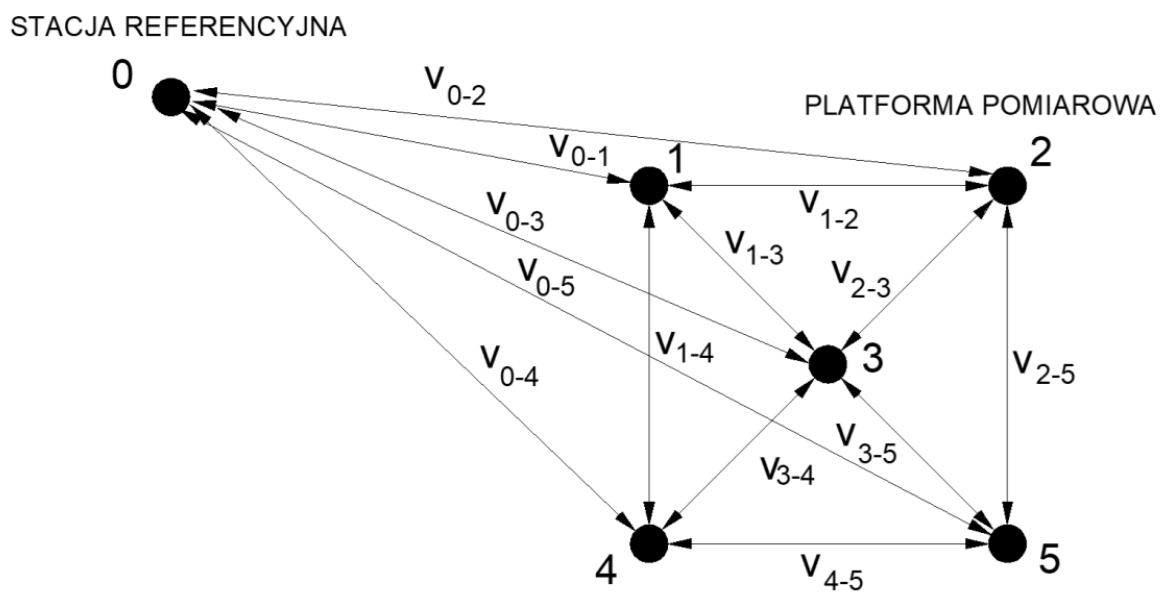

1. A set of vectors defined between the measuring platform and a reference station to align the measurement results: $\mathrm{v}_{0^{-}}{ }^{-}-$long vectors between the reference station and the platform moving on the track; $\mathrm{v}_{i^{-} j}-$-vectors between measuring platform receivers, $i=1-5, j=1-5, i \neq$

$$
j
$$

To determine the trajectory of a rail vehicle, GNSS+INS will be measured while the vehicle is moving (alternatively: train, draisine, traction vehicle, etc.) at elevated speeds. Increased speeds (originally set at $100-120 \mathrm{~km} / \mathrm{h}$ ) refer to the range of speeds preceding the high speed, the limit of which is determined by $v=200(250) \mathrm{km} / \mathrm{h}$, depending on how the speed is implemented (modernization of the existing line, construction of a new line). Therefore, there are a number of problems regarding obtaining the uniqueness of the vehicle's position with the required spatial density and related to appropriately fast data transmission. The project involves testing the current possibilities of determining the position of a vehicle traveling at a speed higher than $120 \mathrm{~km} / \mathrm{h}$, using the latest GNSS techniques and postprocessing with corrections broadcast by reference stations of the terrestrial network.

The research team's previous experience focused mainly on the possibilities of reproducing geometric systems in the conditions of developing satellite systems, in particular after the commissioning of the EUPOS ASG reference station network. The introduction of this network resulted in a radical improvement in the level of obtained accuracy of track position determination. Also undertaken works related to the design of the receiver system and their mutual configuration on measuring platforms resulted in the improvement of the quality of the obtained research results. The already mastered techniques will be further developed to achieve the maximum possible accuracy when identifying the actual shape of the railway lines.

Another important issue related to the implemented project is the issue of an IT system supporting the measurement and analytical process. The techniques used in the project require professional system support. This is due to the fact that the measurements will provide a large amount of information due to the measurement density (sampling frequency) and the redundant configuration of the measuring system sensors (responsible for the method's reliability), as well as due to the functionality in the process of analysis and presentation of results. For this reason, an appropriate IT system based on layer architecture will be developed and manufactured. This architecture will provide effective support for computational processes whose functionality will result from the needs reported by PKP PLK S.A. It also assumes consultations and arrangements regarding the functionality of the system. Figure $\mathbf{2}$ presents the system architecture and the way it is implemented in general. 


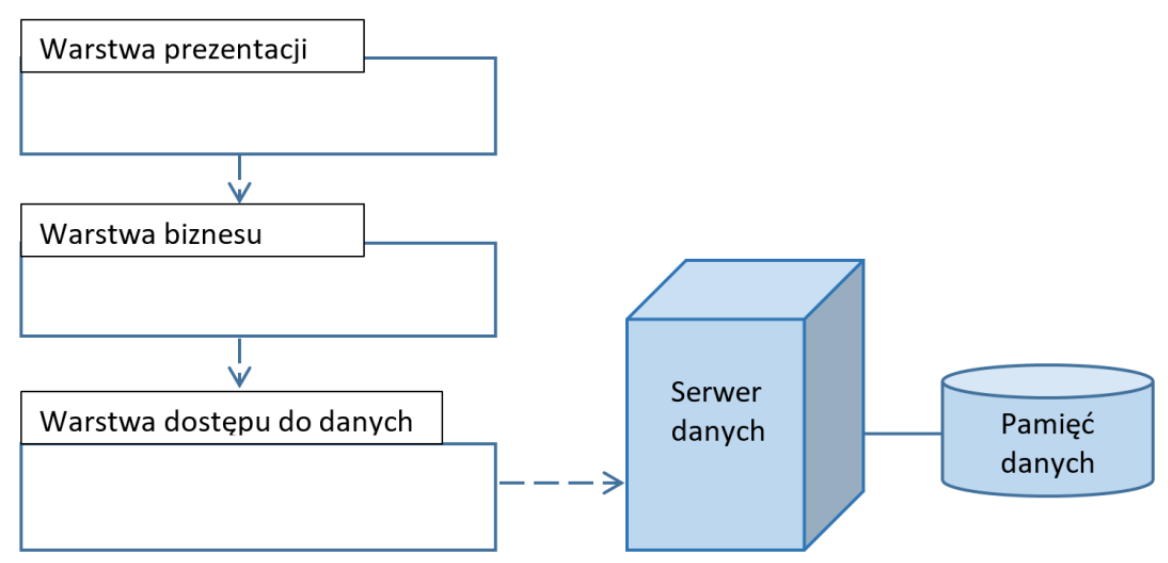

2. The architecture of the IT system and the way it is implemented

It is assumed that the measurement data sets from the GNSS antennas of the measurement platform will be properly ordered and collected in the Microsoft SQL Server database or other database indicated by PKP PLK S.A. It is proposed to develop an IT system as an ASP.NET (Active Server Pages) Internet application in the .NET Framework environment. It will be able to run from any computer connected to the Internet. The system will have the following layers: presentation, business, and database access. Efficient and multi-valued data controls will be implemented in the application. The controls that implement the automatic data binding mechanism and provide a number of operations, such as sorting and filtering, will be selected. It is assumed that the project results will reach a high pre-implementation level. The developed measurement methodology and the method of analyzing the results, implemented with the appropriate functions of an IT system prototype, will allow starting the process of implementing these results. The results of research and detailed technical specifications enabling the implementation of the measurement and analytical methodology by the railway infrastructure manager will be forwarded to PKP PLK S.A.

\section{Stages of project implementation}

The project will comprise nine stages. The following is their brief description.

Stage 1: Development of a methodology for assessing the shape of the railway track using a mobile measuring system and creating a detailed research concept

When using the results of satellite measurements to determine the geometrical shape of the railway axis, theoretical models preferred by some scientific environments, such as, for example, contained in theorem [18]: "... Vehicle trajectory, determined in the form of discrete point series, converted into smooth curves (straight and regression curves) identify the track axis. The use of the LRS (Linear Referencing Segmentation) mathematical formula enables the conversion of the LRS linear system into any surface coordinate system, which makes it possible to integrate GIS (Geographic Information System) with railway systems that locate objects relative to a kilometer." The shape of the track axis must, after all, meet the principles of designing geometrical systems of railway lines and in no case may it take the form of a variable curvature over a considerable length (except for precisely defined sections of transition curves). 
During the implementation of the first stage of the project, a detailed concept and methodology for inventory testing of railway lines and positioning of trains on routes will be prepared. All assumptions of the concept and method will result from the analysis of currently used procedures for determining the track axis and positioning of vehicles on the lines of PKP PLK S.A. The basic assumption is to develop rules for assessing track formation based on modern satellite positioning methods. It is assumed to carry out a detailed analysis of the introduction of GNSS and INS techniques for the purpose of determining the track axis and vehicle position relative to the existing kilometer of the railway line in the PUWG 2000 system. Due to the dynamic development of measuring techniques, it is necessary to refer to the current state not only within the functioning of PKP PLK S.A.

As part of this stage, it is also envisaged to design a mobile measuring platform adapted to the installation of the following system components: satellite antennas and inclinometers, accelerometers, 2D laser scanners constituting a complementary measurement system that allows taking into account the impact of platform movement dynamics on the results of basic measurements.

\section{Stage 2: Development of a mobile GNSS+INS measurement methodology and a detailed concept of measuring data processing}

The basic goal of the second stage is to build a mobile measuring platform adapted to precise satellite measurements. It will be integrated with INS inertial navigation systems and the SL mobile laser scanner. This will allow for precise, accurate and relatively fast and relatively cheap determination of the track axis. The proposed technological solutions will also contribute to increasing the accuracy of determining the trajectory of rail vehicles with increased speed. The detailed design of the measurement platform will take into account multi-criteria analysis regarding the optimal location for mounting components of the GNSS/INS/LS system in the aspect of increasing the level of accuracy of track axis determination. Two multi-variant strategies for determining track axes with high precision will be proposed, which will be based on real-time GNSS positioning (RTK) and on postprocessing development of phase observations. It is anticipated that in general cases, the proposed GNSS strategy will ensure the expected accuracy of track axis determination. In special cases (no GNSS signal - e.g. measurement in tunnels), maintaining high measurement accuracy will ensure the use of integrated GNSS/INS/LS measurements. The subject of analyzes will also be to determine the optimal number of GNSS measuring receivers.

The next step will be to analyze the possibilities of improving the level of accuracy in determining the position of the vehicle on the basis of data obtained from railway carriers' vehicles. In this case, a real-time measurement strategy will be proposed, including receiving position corrections from physical reference stations. For this purpose, active reference station networks available in Poland will be analyzed, i.e. geodetic networks: ASG-EUPOS, VRSnet, Leica and TPI NETpro. A route of empirical analyzes will be designed, taking into account various variants of field barriers, i.e. exposed areas, built-up areas, and wooded areas. As part of the second stage, multi-criteria analysis of operational parameters and properties of INS devices, GNSS receivers and laser scanners available on the market will also be carried out. This stage will end with the selection of the necessary geodetic apparatus and its assembly on a mobile measuring platform.

Stage 3: Construction of information algorithms for analyzing the measurement signal defining the axis of the railway track taking into account the principles of designing railway lines

As part of the third stage, work is planned on the development of algorithms that support the definition of the geometrical system of the railway line, adapted to satellite measurements and 
complementary inertial measurements and laser scanning. The algorithms will be implemented in the selected development environment. Testing of these algorithms is an important element of the project due to the nature of the input data in the form of large sets of coordinates obtained from post-processing measurement and analysis. As a final result of the stage, it is planned to prepare a report containing a discussion of proprietary IT algorithms for processing the final developed measurement data for the purpose of identifying geometrical parameters of railway lines. The detailed architecture of the algorithms and their use will be also presented, as well as the results of preliminary analyzes performed in the test IT environment..

\section{Stage 4: Construction of theoretical models analyzing the measurement signal and defining the vehicle trajectory and railway track axis, taking into account the geodetic calculus algorithms}

As part of the fourth stage, numerical algorithms will be developed to determine the coordinates of the track axes with the assumed high level of accuracy, as well as to determine the trajectory of vehicles at elevated speed while maintaining high positioning precision. The first issue will be closely related to the designed mobile measuring platform. Two approaches to determining the track axis will be considered, i.e. in real-time and through post-processing development of satellite observations.

The measuring platform will consist of three to five GNSS measuring stations. Each of these stations will be equipped with instruments for precise, forced centering of the GNSS antenna. In addition, each of the designed points will be measured in a long GNSS static session, thus determining the distance between the measuring points with high accuracy. This design enables the creation of a GNSS vector network on the measuring platform, which in post-processing data processing will be aligned in relation to the reference station network of ASG-EUPOS, VRSnet, TPI NETpro, and Leica systems. Additionally, various combinations of observation integration from GNSS systems (i.e. GPS, GPS + GLONASS, GPS + BeiDou) will be considered. Equipping the measuring system with the technique of inertial measurements and laser scanning will ensure the maintenance of the assumed level of precision of determination in the event of loss of the GNSS phase solution. Determining the vehicle's trajectory at an increased speed while maintaining high precision will be done by installing four GNSS receivers on the roof of the locomotive. Each receiver will be connected to another active network of reference stations. As before, various options for integrating observations obtained from different GNSS systems will be proposed.

\section{Stage No. 5: Experimental and measurement works aimed at assessing the effectiveness of the proposed algorithms}

The specificity of the implementation of measurements using the active GNSS geodetic network, with the geodetic service of the railway route, is associated with covering considerable distances during measurements. While traveling on the railway track, GNSS receivers used to determine vehicle trajectories and track axes will dynamically change the configuration of the GNSS reference stations used, hence the important cognitive geodetic problem will be the optimization of the use of ASG-EUPOS, VRSnet, Leica, TPI NETpro from the point of view of the criterion a precision. A comparative analysis of GPS differential transmission methods (FKP, MAC, VRS, and others), available services (NAVGEO, KODGIS, NAVGIS) and the used version of the telemetry standard (RTCM) from the point of view of minimizing the error of coordinate determination in vast areas are expected. The use of inertial systems makes it possible to maintain high accuracy in determining the track axis in situations of temporary loss of the GNSS phase solution, e.g. when traveling under a viaduct or when limiting the visibility of satellites through buildings or terrain. Integrated 
GNSS/INS technology will therefore significantly increase the availability, reliability, and continuity of determination. The integration of GNSS / INS measurements with the results of the point cloud analysis obtained from the laser scanner measurement will mean supplementing the system capabilities with the use of redundant measurements.

Empirical research on determining the trajectory of vehicles with increased speed will be carried out in vast areas that will be characterized by variability of terrain screens. The basis for this issue are differential RTK measurements in real time, taking into account position corrections obtained from active reference station networks. As part of the experiments carried out, the area available within one reference station will be examined. It should be noted that the measurements on the test objects will be repeated, taking into account the different positions of the GNSS satellites in orbit. The impact of the number of satellites adopted for the phase solution will also be analyzed, resulting from including next to GPS satellites transmitters of other satellite systems, i.e. Galileo, GLONASS and BeiDou. Such solutions will allow modeling of the constellations of satellites, including DOP coefficients (decisive for accuracy).The empirical studies of track axis determination will concern both real-time positioning and post-processing development of satellite observations. As a result of the implementation of geodetic tasks, the coordinates of the track axis will be obtained determined by different techniques, with different levels of accuracy. As part of the fifth stage, there will be metrological analysis of measurement uncertainty for individual variants and selection of the most effective, i.e. the most accurate method of determining the track axis.

\section{Stage 6: Development of an IT system using field measurement results in managing the rail road network}

The developed algorithms and theoretical models of geometrical systems will undoubtedly be valuable tools, but only implemented in the IT system will allow them to be fully used in engineering practice. Such a system should be made with the entire investment process in mind, thus taking into account the nature of design processes (both concepts and detailed executive project), railway lines management and their operation. For this reason, the IT system will be designed in the form of a database and modules supporting the most important design and analytical processes as well as railway line management processes. It is assumed that the measurement data sets from GNSS antennas will be properly ordered and collected in the Microsoft SQL Server database or Access database. The database indicated by PKP PLK S.A. may also be included. It is proposed to develop an IT system as a web application with the implementation of the so-called business rules in order:

- automating the integration of post-processing data from mobile GNSS measurement with INS and IMU systems,

- increasing the accuracy of the railway track graph as a reference system for railway systems and their conversion into spatial coordinate systems.

\section{Stage 7: Development of an IT system supporting the analysis of field measurement results}

The methods of determining the track axis coordinates and vehicle trajectories proposed in the previous stages require specialized tools for visualization and analysis of the results obtained. To this end, a software prototype will be proposed to enable:

- post-processing calculation of the coordinates of GNSS receivers located on the measuring platform,

- calculation of discrete representations of track axes based on GNSS/INS measurements,

- graphic presentation of track axis points on the map,

- visualization of vehicle trajectories on the map (based on results files from RTK positioning), 
- the coordinate transformation between the PUWG2000 global system and the local coordinate system used by PKP PLK S.A.,

- entering coordinates of a kilometer and hectometers signs, along with their visualization on the map,

- determination of the nearest kilometer and hectometers signs occurring between given track axis points (accident identification system).

The developed program will have an interface that allows you to navigate the database and computing modules and allows you to view the results obtained on map studies.

\section{Stages 8 and 9: Developing reporting documentation, determining how to implement the project effects.}

The works under stages eight and nine will consist of complete documentation of the results obtained as a result of work carried out in earlier stages. To this end, numerous consultation meetings will be necessary to formulate correct final conclusions. Administrative work carried out by the project management team will also be completed. Directions of implementation of the works carried out by way of arrangements with PKP PLK S.A. will be determined. As a final result, a cumulative report will be prepared to contain complete documentation of theoretical research and fieldwork carried out, along with a prototype of the IT system. At this stage, the R\&D team will prepare the final reporting on their research.

\section{Research carried out by the Gdańsk University of Technology}

The implementation of the InnoSatTrack project in 2018 by the Gdańsk University of Technology under stage 1 included several specific tasks, which are described below.

\section{Analysis of methods for determining and assessing track shape}

As part of this task, substantive analysis of a number of scientific publications and applicable regulations regulating the issue of determining and assessing track shape in Poland and abroad was carried out. Determining and assessing the shape of the railway track concerns, more precisely, the geometrical arrangement of the track axis. The purpose of this operation is to determine the basic geometric parameters of the route such as:

- location and length of straight sections,

- location of circular arcs together with the specification of their radius and length,

- location of transition curves with specification of their type and length.

On the basis of these data, it becomes possible to simulate the train passing on a given geometrical system (and thus to determine the maximum speed possible to achieve), as well as - which seems to be the basic issue - to obtain data aimed at determining the places of potential track axis corrections and carrying out projects needed to regulate it.

The track axis coordinates should be measured using a satellite dish set in the track crosssection axis, with its upper surface leveling at the height of the line connecting the two rail tracks at the place where the current track width is determined. In mobile satellite measurements, such a solution is impossible to implement, since it is not feasible to attach the GNSS antenna to the measuring wagon structure so that it is at the height of the rail heads. In practice, the antenna is installed at a certain height relative to the required level, resulting from the dimensions of the wagon, the dimensions of the system fixing the antenna to its floor, as well as the dimensions of the antenna itself. In this situation, the measured satellite coordinates of the track axis are affected by an error, which should be unconditionally eliminated. This will become possible if an inclinometer is mounted near the antenna installed in the place where the bogie pivot is located, which will allow the measurement of the longitudinal and transverse tilt angles of the measuring car frame. 


\section{The concept of research on railway trajectories using satellite navigation}

The research on the trajectories of railway lines using satellite navigation consists in carrying out mobile satellite measurements using the most modern measuring equipment. The main assumption is to carry out the measurement at a speed of $10-30 \mathrm{~km} / \mathrm{h}$, which will make the inventory measurement relatively fast [7]. Within this task, a number of analyzes were carried out, as a result of which assumptions were made regarding the technique of mobile satellite measurements. These assumptions were verified by performing preliminary experimental tests (during measurements carried out on the tram network in Gdańsk). It should be noted that the scientific team has extensive experience in the application of advanced measurement techniques on the railway $[1,7]$.

Computational methods have also been developed that allow the determination of antenna position correction values in the longitudinal profile and cross-section so that you can then make corrections to the track axis coordinates. Having corrected coordinates makes it possible to carry out subsequent stages in the process of determining the trajectory of a rail vehicle (identifying the shape of the track axis), i.e.:

- determining the location of straight sections,

- determination of route return angles,

- estimation of the radius of circular arcs,

- track axis shape identification by computer iteration (using the computational algorithms described in [7] and new applications written for the project).

\section{Impact of measuring wagon dynamics on track location measurements using mobile GNSS/INS techniques}

Geometric parameters of railroad tracks (curvature, slope, the variable distance between railways, unevenness of railheads, etc.) and clearances resulting from the structure of the wagon translate into the displacement of the wagon frame along with the measuring platform on which the satellite antennas are mounted. There is, therefore, a change in the position of the antenna attachment points relative to the rail lines. The analysis of the kinematic and kinetic properties of the measuring car (bogies and frame) is necessary to examine the effect of antenna displacement relative to rail lines during mobile satellite measurements on the measurement result. As part of the project, this problem will be solved by an analytical and experimental approach.

Within the scope of this task, a study of analytical methods was carried out to formulate equations of motion for a railway measuring wagon. An analysis of the possibilities of using $\mathrm{CAD} / \mathrm{CAE}$ computer programs for the needs of dynamic simulation of a measuring wagon was also carried out, using extensive experience gained in this field, obtained in dynamic simulations of various kinematic objects used in electric traction [17].

An analysis was also made regarding the measurements of the wagon inclination and its vibrations during mobile measurements. A complementary measurement system was proposed, which includes: inclinometers, accelerometers and optionally electronic speed gyroscopes for dynamic parameters acquisition. A study of the application of vision systems and laser scanning in mobile measurements was also conducted to analyze the displacement of the measurement platform relative to rail tracks. They were successfully used in diagnostics of overhead contact lines and current collectors $[1,10]$.

\section{Measuring platform design}

The measuring platform is a mechanical system dedicated to attach tribrachs on which satellite dishes are mounted. This structure must be fixed to the wagon frame in a reliable, stable manner, allowing relatively quick assembly and disassembly. Its movement is not 
allowed during mobile measurements. Within the scope of the discussed task, requirements for the expected properties of the measuring platform were formulated. Then, an analysis of available rail vehicles was carried out from the point of view of their use as a measuring vehicle for the needs of mobile satellite measurements. This analysis shows that a $401 \mathrm{Z}$ platform wagon can be used for such purposes. Then, a review of selected propulsion units was carried out. It allowed the selection of the WM-15 draisine as a suitable traction vehicle for these needs. In relation to the above-mentioned activities, design of the measurement platform construction dedicated to the $401 \mathrm{Z}$ wagon was developed (Fig. 3). This design is scalable due to the modularity of its essential components and meets the requirements of mobile satellite measurements.

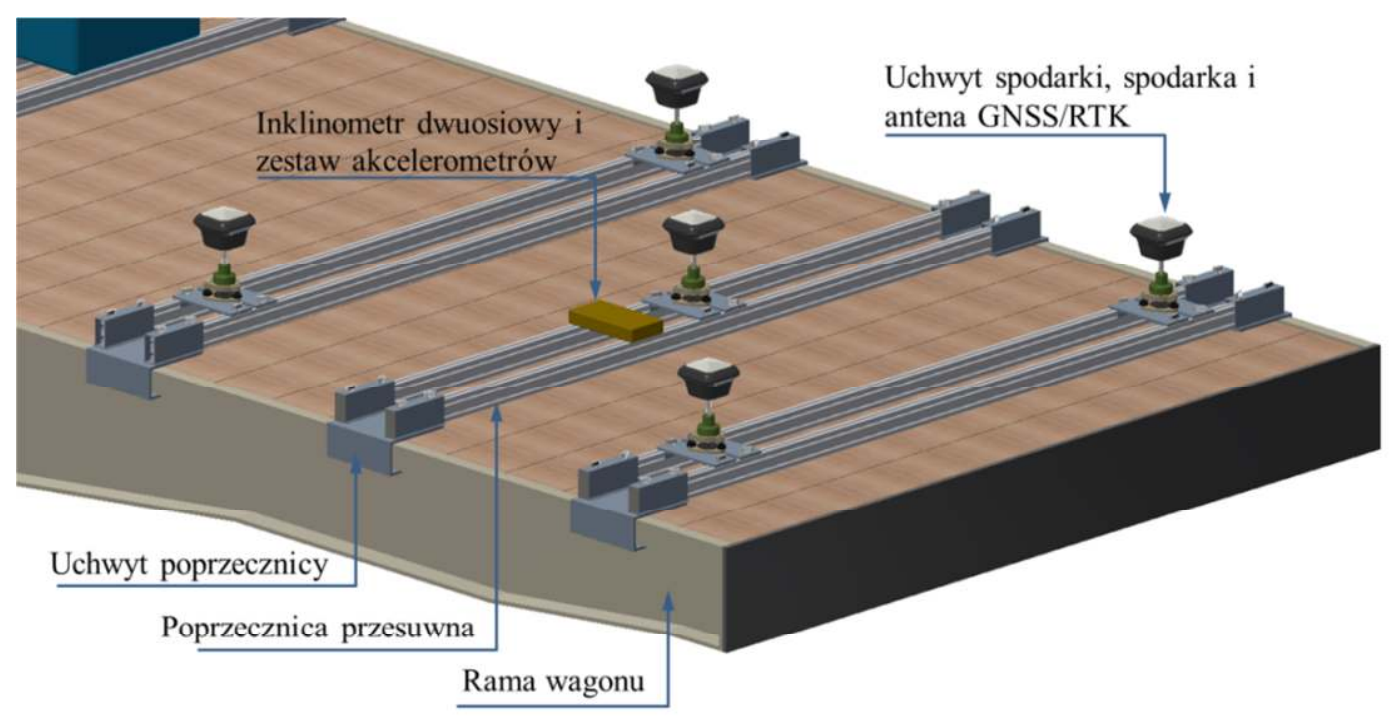

3. A computer $3 \mathrm{D}$ model of the measuring platform as a modular structure installed on the frame of the $401 \mathrm{Z}$ wagon

\section{Testing of the measuring platform in the scope resulting from stages 1 and 2}

The prototype of the proposed construction of the measuring platform was made in a version intended for one type of tram bogies and experimentally tested in field conditions - on a real tram track during mobile test measurements. Figure $\mathbf{4}$ shows the view of the measuring unit during mobile measurements in the tram track.

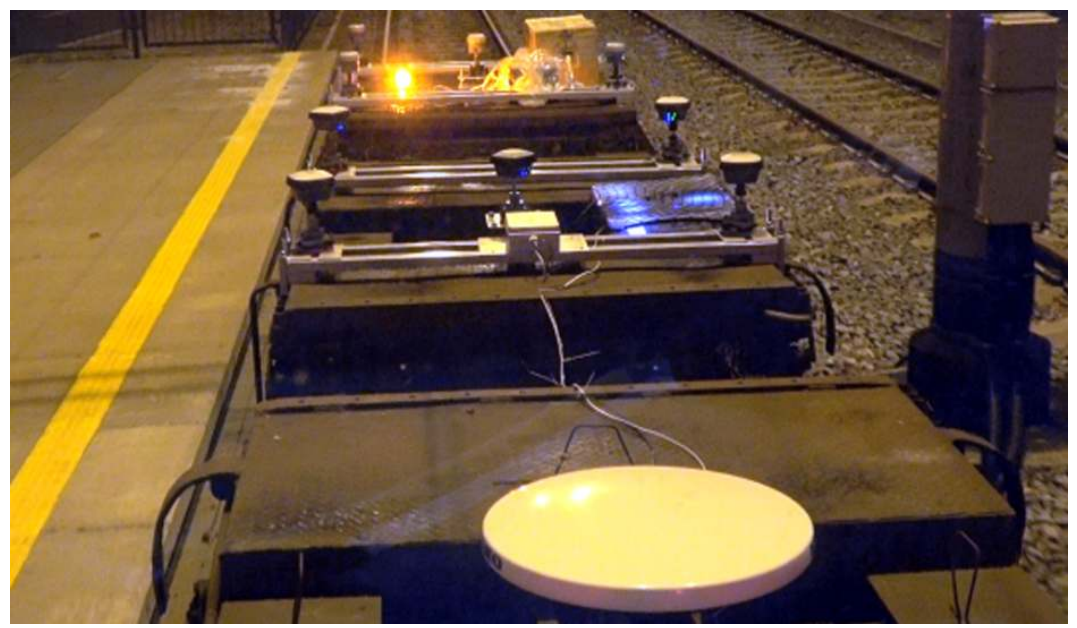

4. Test set during mobile tests in a real track 
Field tests confirmed the validity of the concept of the measuring platform as a mechanical system with a cross member structure in relation to the wagon frame and as a modular system allowing for the effect of scalability.

\section{Research carried out by the Maritime University of Gdynia}

The scientific team of the Maritime University in Gdynia carried out individual research tasks by performing a number of specific tasks. A synthetic description of the research work carried out in 2018 was presented.

\section{GNSS/INS/MLS technologies in track shape measurement}

The scope of activities undertaken as part of the first scientific task concerned geodetic analyzes of methods for determining the geometrical shape of the track axis, currently used by PKP PLK S.A., along with determining their accuracy. Fieldwork in this type of engineering issues is generally carried out using classical measurement methods based on total station. Due to the fact that geodetic inventory of tracks concerns mainly vast areas (e.g. railway lines characterized by several or several hundred kilometers in length), the implementation of such works requires the participation of a significant number of employees and the disposal of a large number of measuring equipment. The consequence of this is a long time of geodetic works, which also requires significant financial outlays. For this reason, the scope of analyzes has been expanded to include innovative methods that guarantee the determination of the geometrical shape of the track axis by means of mobile measurements.

Measurement methods using mobile measurement platforms (MPPs) are among the latest and most important global solutions in broadly understood railway engineering. It should be noted that Polish scientists actively involved in the implementation of this research project have a significant contribution to the development and promotion of this type of solutions [12, 13]. Mobile measurements in railway engineering are carried out using the GNSS satellite positioning technology, which, among other things, due to the need to maintain the continuity of position determination in the event of loss of GNSS signal, is generally supported by inertial navigation technology (INS). Integration of GNSS and INS measurements is possible through the use of specialized calculation procedures, known among others from the geodetic equalization account, i.e. the Kalman filter, as well as its resistant version. In addition, the architecture of the measuring system is often supplemented with a laser scanner (MLS Multiwave Locked System). An example of an MPP equipped in this way is shown in Figure 5.

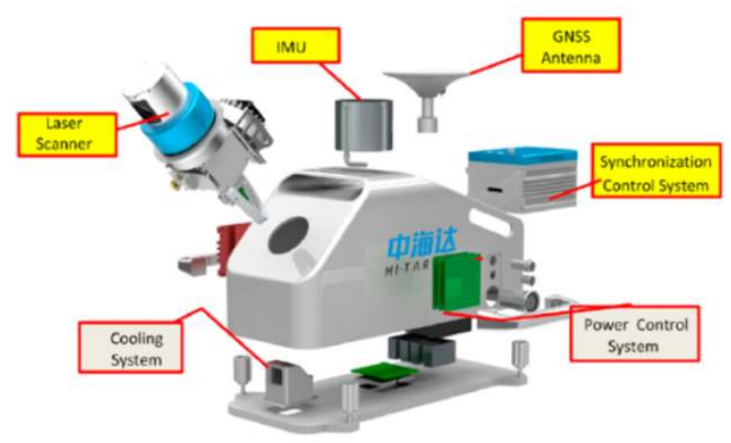

(a)

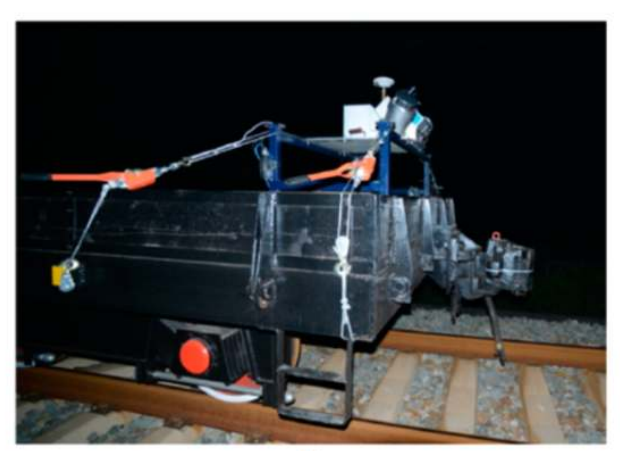

(b)

5. An example of the GNSS/INS/MLS measurement architecture, used in the research described in [19]: a) view of the device; b) measuring platform 
It should be noted, however, that the level of accuracy of MLS measurement results depends on the precision of GNSS position determination. A similar situation occurs when predicting the location of GNSS receivers based on kinematic information. For this reason, subsequent scientific research carried out in 2018 as part of stage 2, concerned the issue of increasing the accuracy of position determination based on mobile GNSS measurements.

\section{Design and implementation of a mobile measuring platform}

The work carried out under the second task concerned the development of an ideological diagram of the mobile measuring platform (MPP). Analyzes carried out as part of the first scientific task have shown that the current approach to the issue of determining the indicators of geometrical track formation using mobile measuring platforms was basically based on the use of only one GNSS receiver. Researchers from the Gdynia Maritime University proposed to supplement the measurement system architecture with additional GNSS receivers. The schematic diagram of the arrangement of additional GNSS receivers has been presented in Figure 6.

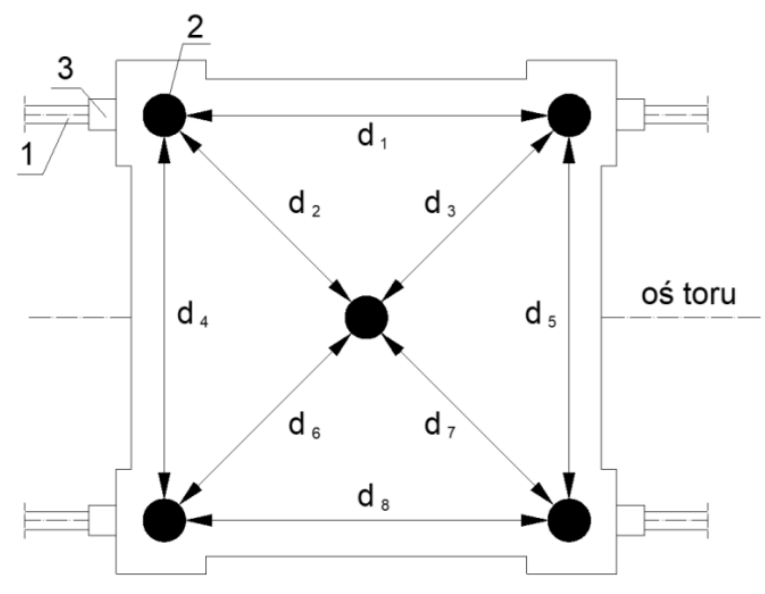

6. Schematic diagram of the mobile measuring platform: 1 - railways, 2 - points for forced centering of the GNSS receiver, 3 - platform wheels, $d_{i}$ - the distance between the centering points of GNSS receivers

It is assumed that ultimately there will be up to five GNSS receivers on the MPP surface. Based on the measurements carried out using these receivers, the final coordinates of the measuring platform will be calculated. This will be done by determining the arithmetic mean position of all receivers, or based on other geometric conditions related to the designed measuring structure. Figure 7 presents selected possible variants of GNSS receiver placement in the track axis determination process. 


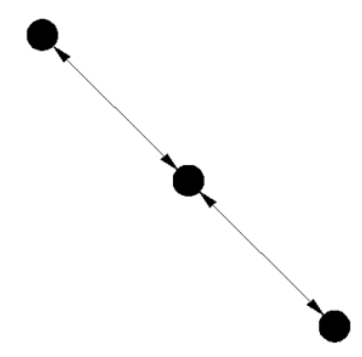

a) Układ diagonalny

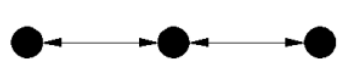

b) Układ podłużny

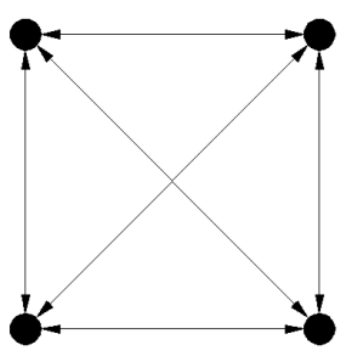

c) Układ czworoboku

7. Selected variants of the arrangement of GNSS receivers relative to the longitudinal axis of the platform in the process of determining the track axis

The ideas for solutions proposed at this stage of research work concern both the issue of real-time positioning and the development of "raw" measurement data in post-processing mode. It should be noted, however, that these works are also particularly important in the context of the implementation of the third research task, which includes analyzes aimed at increasing the accuracy of GNSS positioning in mobile measurement conditions, including the optimization of the number of GNSS receivers involved in the measurement and selection appropriate measuring apparatus.

\section{Possibilities to improve the accuracy of the train location method currently used in PKP}

As part of the work on the third scientific task, theoretical analyses were carried out to increase the accuracy of GNSS positioning in mobile measurement conditions. Preliminary measurements were also carried out on a prototype of the measuring platform developed by the PG scientific team, whose main goal was to select the appropriate measuring apparatus and optimize the number of GNSS receivers for the measurement of track configuration. These measurements were carried out using GNSS receivers made available by Leica and Trimble. Receiver tests concerned both real-time positioning (RTK) and data processing from satellite observations in post-processing mode. For the purposes of the research, a measuring structure was designed and developed, which includes two mobile measuring platforms on which the receivers of the above-mentioned companies were installed. A schematic diagram of the measuring structure is shown in Figure 8.

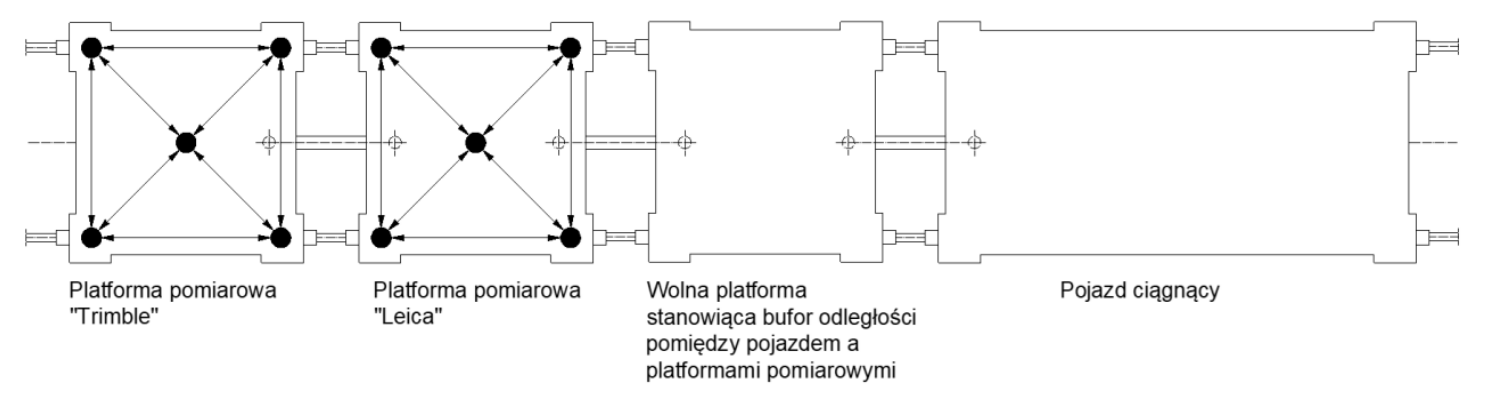

8. Schematic diagram of the measuring structure used in preliminary measurements

The measurement works were preceded by theoretical analyzes concerning - among others - GNSS geodetic networks in Poland and the standard of geodetic and navigation data transmission. This work is particularly important due to the fact that each GNSS network has a different number of reference stations in which GNSS observations are carried out permanently. Other differences regarding reference stations may relate to the measuring 
apparatus installed on them, the type of GNSS signals received and the version of corrections made available in real-time, and as a consequence the positioning accuracy. A total of ten receivers were used in the preliminary measurements: five Leica GS18T receivers and five Trimble R10 receivers, which - using the SmartNET (Leica) and VRSNet (Trimble) reference stations network - enabled the recording of high accuracy position data in real-time at frequency 1 h. Maps of reference stations of these networks are presented in Figure 9.

a)

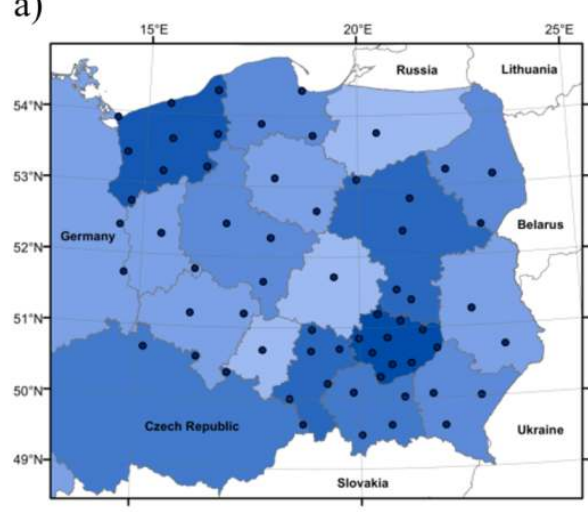

b)

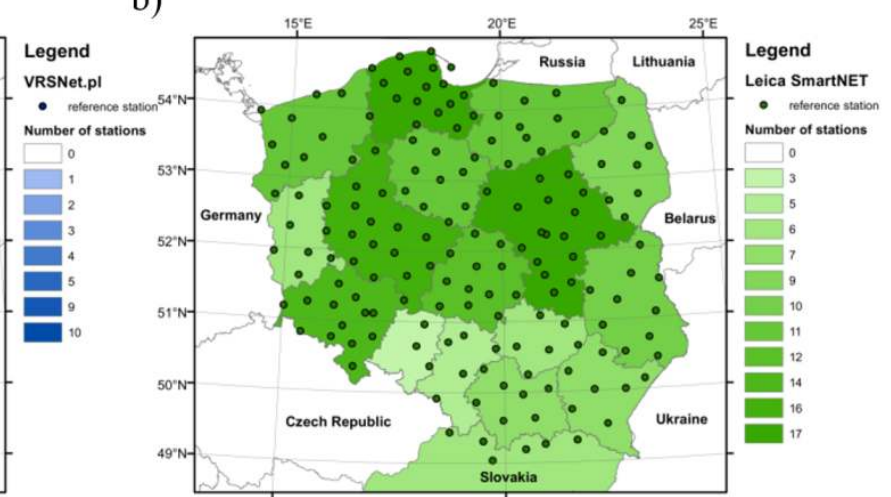

9. Maps of reference stations: a) VRSNet (Trimble); b) SmartNe networkst (Leica)

The theoretical part of the analyzes has been supplemented with the characteristics of other reference station networks operating in Poland, i.e. TPI NETpro and ASG-EUPOS. As part of the initial measurements, observational data was also recorded without corrections from reference stations at $20 \mathrm{~Hz}$.

\section{Conclusions}

The assumptions of the innovative rail track location system based on mobile measurements based on satellite location discussed in the article indicate the complexity of the problem being solved. Analysis of the application of the latest measuring techniques based on multistage computer processing of data both during the measurement and as part of the so-called post-processing, allow the formulation of the thesis that it is possible to determine the location of the railway track based on mobile measurements while maintaining the level of accuracy characteristic of stationary total stations. The first field tests carried out to demonstrate the validity of the adopted measurement concept and initially confirm the thesis formulated. As part of further work, a measuring platform is planned for the needs of measuring on railway lines. Performing these measurements and confirming the results obtained by comparing them with current measurement methods will allow final confirmation of the thesis and preparation of the system for commercial implementation.

\section{Source materials}

[1] Bartłomiejczyk M., Jarzębowicz L., Judek S., Karkosińska-Brzozowska N., Karwowski K., Mizan M., Skibicki J., Wilk A.: Energetyka transportu zelektryfikowanego. Poradnik inżyniera. Wydawnictwo Politechniki Gdańskiej, Gdańsk 2018.

[2] Gucma M., Montewka J.: Podstawy morskiej nawigacji inercyjnej. Wydawnictwo Akademii Morskiej w Szczecinie, Szczecin 2006.

[3] Koc W., Specht C.: Wyniki pomiarów satelitarnych toru kolejowego. Technika Transportu Szynowego 2009, tom 15, nr 7-8, s. 58-64. 
[4] Koc W., Specht C.: Selected problems of determining the course of railway routes by use of GPS network solution. Archives of Transport 2011, Vol. XXIII, Issue 3, pp. 303-320.

[5] Koc W., Specht C.: Zastosowanie mobilnych pomiarów satelitarnych w projektowaniu i eksploatacji dróg szynowych. Problemy Kolejnictwa 2015, tom 59, z. 166, s. 63-83.

[6] Koc W., Specht C., Chrostowski P.: Finding deformation of the straight rail track by GNSS measurements. Annual of Navigation 2012, No. 19, part 1, pp. 91-104.

[7] Koc W., Specht C., Chrostowski P.: Projektowanie i eksploatacja dróg szynowych z wykorzystaniem mobilnych pomiarów satelitarnych. Wydawnictwo Politechniki Gdańskiej, Gdańsk 2018.

[8] Liu C., Li N., Wu H., Meng X.: Detection of high-speed railway subsidence and geometry irregularity using terrestrial laser scanning. Journal of Surveying Engineering 2014, Vol. 140, Iss. 3.

[9] Rozporządzenie Rady Ministrów z dnia 15 października 2012 r. w sprawie państwowego systemu odniesień przestrzennych. Dz. U. R. P. z 2012 r., Poz. 1247.

[10] Skibicki J.: Wizyjne metody pomiarowe w diagnostyce górnej sieci trakcyjnej. Wydawnictwo Politechniki Gdańskiej, Gdańsk 2018.

[11] Specht C.: System GPS. Wydawnictwo Bernardinum, Pelplin 2007.

[12] Specht C., Dąbrowski P., Specht M., Koc W., Chrostowski P., Szmagliński J., Dera M., Skóra M.: Mobilne pomiary satelitarne na liniach Pomorskiej Kolei Metropolitalnej. Przegląd Komunikacyjny 2016, rocznik LXXI, nr 5, s. 9-16.

[13] Specht C., Koc W.: Mobile satellite measurements in designing and exploitation of rail roads. Transportation Research Procedia 2016, Vol. 14, pp. 625-634.

[14] Specht C., Koc W., Chrostowski P., Szmagliński J.: The analysis of tram tracks geometric layout based on mobile satellite measurements. Urban Rail Transit 2017, Vol. 3, Iss. 4, pp. 214-226.

[15] Specht C., Koc W., Smolarek L., Grządziela A., Szmagliński J., Specht M.: Diagnostics of the tram track shape with the use of the global positioning satellite systems (GPS/Glonass) measurements with a $20 \mathrm{~Hz}$ frequency sampling. Journal of Vibroengineering 2014, Vol. 16, Iss. 6, pp. 3076-3085.

[16] Specht C., Nowak A., Koc W., Jurkowska A.: Application of the Polish Active Geodetic Network for railway track determination. Transport Systems and Processes Marine Navigation and Safety of Sea Transportation, CRC Press - Taylor \& Francis Group 2011, London, UK, pp. 77-81.

[17] Wilk A.: Novel analysis methods of dynamic properties for vehicle pantographs. MATEC Web of Conferences 2018, Vol. 180, 01005, pp. 1-6.

[18] Zakres tematyczny konkursu 1/4.1.1/2017/POIR realizowanego w ramach Wspólnego Przedsięwzięcia pn.: „Badania i Rozwój w Infrastrukturze Kolejowej - BRIK”. Załącznik nr 1 do Regulaminu Konkursu, Narodowe Centrum Badań i Rozwoju, Warszawa 2017. Źródło dostępu (19.02.2019): https://www.ncbr.gov.pl/programy/funduszeeuropejskie/poir/konkursy/konkurs14112017-brik/

[19] Zhou Y., Wang S., Mei X., Yin W., Lin C., Hu Q., Mao Q.: Railway tunnel clearance inspection method based on 3D point cloud from Mobile Laser Scanning. Sensors 2017, Vol. 17, Iss. 9, 2055, pp. 1-20. 